Article

\title{
Integration of miRNA and mRNA Co-Expression Reveals Potential Regulatory Roles of miRNAs in Developmental and Immunological Processes in Calf Ileum during Early Growth
}

\author{
Duy N. Do ${ }^{1,2}$, Pier-Luc Dudemaine ${ }^{1}$, Bridget E. Fomenky ${ }^{1,3}$ and \\ Eveline M. Ibeagha-Awemu 1,*(D) \\ 1 Agriculture and Agri-Food Canada, Sherbrooke Research and Development Centre, \\ Sherbrooke, QC J1M 0C8, Canada; DuyNgoc.Do@AGR.GC.CA (D.N.D.); \\ Pier-Luc.Dudemaine@AGR.GC.CA (P.-L.D.); bridget.fomenky.1@ulaval.ca (B.E.F.) \\ 2 Department of Animal Science, McGill University, Ste-Anne-de-Bellevue, QC H9X 3V9, Canada \\ 3 Département de Sciences Animale, Université Laval, Quebec, QC G1V 0A6, Canada \\ * Correspondence: eveline.ibeagha-awemu@agr.gc.ca; Tel.: +1-819-780-7249
}

Received: 13 August 2018; Accepted: 5 September 2018; Published: 11 September 2018

\begin{abstract}
This study aimed to investigate the potential regulatory roles of miRNAs in calf ileum developmental transition from the pre- to the post-weaning period. For this purpose, ileum tissues were collected from eight calves at the pre-weaning period and another eight calves at the post-weaning period and miRNA expression characterized by miRNA sequencing, followed by functional analyses. A total of 388 miRNAs, including 81 novel miRNAs, were identified. A total of 220 miRNAs were differentially expressed (DE) between the two periods. The potential functions of DE miRNAs in ileum development were supported by significant enrichment of their target genes in gene ontology terms related to metabolic processes and transcription factor activities or pathways related to metabolism (peroxisomes), vitamin digestion and absorption, lipid and protein metabolism, as well as intracellular signaling. Integration of DE miRNAs and DE mRNAs revealed several DE miRNA-mRNA pairs with crucial roles in ileum development (bta-miR-374a—FBXO18, bta-miR-374a-GTPBP3, bta-miR-374a-GNB2) and immune function (bta-miR-15b-IKBKB). This is the first integrated miRNA-mRNA analysis exploring the potential roles of miRNAs in calf ileum growth and development during early life.
\end{abstract}

Keywords: calf; Ileum; miRNA-mRNA integration; miRNA sequencing; growth; development

\section{Introduction}

MicroRNAs (miRNAs) are small ( 22 nucleotides) endogenous RNA molecules that regulate gene expression post-transcriptionally by targeting principally the $3^{\prime}$ untranslated region ( $3^{\prime}$ UTR) of genes and to some extend the $5^{\prime} \mathrm{UTR}$, introns and coding region of mRNAs [1]. They play key roles in a wide range of biological processes [2]. In bovine, miRNAs have been shown to play important roles in embryonic development [3-5], mammary gland [6,7] and adipose tissue [8] functions and also in the regulation of production traits such as milk yield [6,9,10], milk quality [11] and diseases like mastitis [12,13] and Johne's disease [14]. The importance of miRNAs in gut development and disease (mostly inflammatory bowel disease) has been extensively studied in humans [15-18]. For instance, several miRNAs have been reported to be relevant for different aspects of inflammatory bowel disease (IBD), including miRNAs important for intestinal fibrosis (miR-29, miR-200b, miR-21, miR-192), 
epithelial barrier and immune function in IBD pathogenesis (miR-192, miR-21, miR-126, miR-155, miR-106a) [19].

Data from a few studies suggest important roles for miRNAs in calf's early life [20,21]. For instance, Liang et al. (2016a) [21] identified several dominantly expressed miRNAs (miR-143 (30\% of read counts), miR-192 (15\%), miR-10a (12\%) and miR-10b (8\%)) in ileum tissues of dairy calves collected at $30 \mathrm{~min}$ after birth and at 7, 21 and 42 days old. Furthermore, several temporally expressed miRNAs (miR-146, miR-191, miR-33, miR-7, miR-99/100, miR-486, miR-145, miR-196 and miR-211), regional specific miRNAs (miR-192/215, miR-194, miR-196, miR-205 and miR-31) and miRNAs (miR-15/16, miR-29 and miR-196) linked to bacterial abundance in the jejunum and ileum were also reported [21]. Moreover, several ileum miRNAs are reported to play important roles in host responses to Mycobacterium avium subspecies paratuberculosis infection, such as the role of bta-miR-196b in the proliferation of endothelial cells and bta-miR-146b in bacteria recognition and regulation of the inflammatory response [22].

During early life, calves undergo major physiological and digestive changes, including adaptation to diet changes from pre- to post-weaning. The interactions between transcriptional and post-transcriptional mechanisms are known to coordinate these developmental transitions via regulation of gene expression. Recently, we characterized the long non-coding RNA (lncRNA) expression in ileum tissues of calves and functional inference of identified lncRNA (623 known and 1505 novel) cis target genes revealed potential roles in growth and development as well as in posttranscriptional gene silencing by RNA or miRNA processing processes and in disease resistance mechanisms [23]. Moreover, we also observed that 122 miRNAs were significantly differentially expressed between the pre- and post-weaning periods in the rumen, suggesting important roles of miRNAs in calf gut during early life [24]. Therefore, we hypothesize that miRNAs might play important roles in ileum development during the pre- and post-weaning periods. Thus, in the current study, we performed integrated miRNA-mRNA co-expression analyses to uncover the potential roles of miRNAs in ileum development at the pre- and post-weaning periods.

\section{Materials and Methods}

\subsection{Animals and Management}

Procedures for animal management were conducted according to the Canadian national codes of practice for the care and handling of farm animals (http:/ / www.nfacc.ca/codes-of-practice) and approved by the animal care and ethics committee of Agriculture and Agri-Food Canada (CIPA \#442).

Experimental details have been described in our previous studies [23,24]. Briefly, sixteen 2-7 days-old Holstein calves were raised for a period of 96 days in individual pens. In the first week of the experiment, calves were fed milk replacer $(6 \mathrm{~L} /$ day for the first four days and $9 \mathrm{~L} /$ day thereafter, Goliath XLR 27-16, La Coop, Montreal, QC, Canada), and then starter feed (Munerie Sawyerville Inc., Cookshire-Eaton, QC, Canada) was introduced (ad libitum) from the second week. After weaning, calves were fed with starter feed and hay ad libitum. The calves were weighed weekly until euthanization. At experiment D33 (pre-weaning), eight calves were humanely euthanized and another eight calves on D96 (post-weaning), for the collection of ileum tissue samples. Tissues were aseptically collected, snap frozen in liquid nitrogen, and stored at $-80^{\circ} \mathrm{C}$ until used.

\subsection{Total RNA Purification}

Ileum tissue (30 mg/sample) was used for total RNA isolation using miRNeasy Kit (Qiagen Inc., Toronto, ON, Canada). Potentially contaminating genomic DNA was removed by treating $10 \mu \mathrm{g}$ of purified RNA $(10 \mu \mathrm{g})$ with DNase (Turbo DNA-free ${ }^{\mathrm{TM}}$ Kit, Ambion Inc., Foster City, CA, USA). The RNA concentration (before and after digestion) and its quality (integrity) after DNase treatment were assessed with Nanodrop ND-1000 (NanoDrop Technologies, Wilmington, DE, USA) and Agilent 2100 Bioanalyzer (Agilent Technologies, Santa Clara, CA, USA), respectively. The RNA integrity 
number (RIN) of all samples was greater than 8 and a small RNA peak area was visible on the electropherogram [25].

\section{3. miRNA Library Preparation and Sequencing}

Libraries $(n=16)$ were prepared and barcoded for sequencing according to Do et al. [10]. Briefly, polyacrylamide gel electrophoresis was used to size separate miRNA libraries from other RNA species. An elution buffer (10 mM Tris- $\mathrm{HCl}$ pH 7.5; $50 \mathrm{mM} \mathrm{NaCl}, 1 \mathrm{mM}$ EDTA) was used to elute the libraries from the gel. Eluted library was concentrated using DNA clean and concentrator-5 (Zymo Research, Irvine, CA, USA). The concentration of purified libraries was evaluated using Picogreen assay (Life Technologies, Waltham, MA, USA) and a Nanodrop 3300 fluorescent spectrophotometer (NanoDrop Technologies), and further confirmed by qPCR using the Kapa Library Quantification Kit for Illumina platforms (KAPA Biosystems, Wilmington, MA, USA). Libraries were multiplexed in equimolar concentrations and sequenced in one lane on an Illumina HiSeq 2500 platform following Illumina's recommended protocol to generate single end data of 50-bases by The Centre for Applied Genomics, The Hospital for Sick Children, Toronto, Canada (http://www.tcag.ca/).

\subsection{Small RNA Sequence Data Analysis}

Bioinformatics processing of generated small RNA sequences was done as previously described $[10,24]$. Briefly, the raw sequence data (16 fastq files) was checked for sequencing quality with FastQC program v0.11.3 (http:/ / www.bioinformatics.babraham.ac.uk/projects/fastqc/). Trimming of $3^{\prime}$ and $5^{\prime}$ adaptor sequences, contaminants and repeats was accomplished with Cutadapt v1.2.2 (https://cutadapt.readthedocs.org/). Then, FASTQ Quality Filter tool of FASTX-toolkit (http://hannonlab.cshl.edu/fastx_toolkit/) was used to remove reads having a Phred score $<20$ for at least $50 \%$ of the bases and reads shorter than 18 nucleotides or longer than 30 nucleotides. Clean reads that passed all filtering criteria from the 16 files were parsed into one file and mapped to the bovine genome (UMD3.1) using bowtie 1.0.0 (http:/ / bowtie-bio.sourceforge.net/index.shtml) [26]. Reads that mapped to other RNA species (rRNA, tRNA, snRNA and snoRNA) in the Rfam RNA family database (http:/ /rfam.xfam.org/) or to more than five positions of the genome were removed.

\subsection{Identification of Known miRNA and Novel miRNA Discovery}

The identification of known miRNAs was performed with miRBase v21 http:/ / www.mirbase. $\mathrm{org} /$ ) (Kozomara and Griffiths-Jones, 2014), while novel miRNA discovery was achieved with miRDeep2 v2.0.0.8 (https://github.com/rajewsky-lab/mirdeep2) [27]. MiRDeep2 was designed to detect miRNAs from deep sequence reads using a probabilistic algorithm based on the miRNA biogenesis model. The core and quantifier modules of miRDeep2 were applied to discover novel miRNAs in the pooled dataset of all the libraries while the quantifier module was used to profile the detected miRNAs in each library. MiRDeep2 score higher than five was used as cuff point for the identification of novel miRNAs. Subsequently, a threshold of 10 counts per million and present in $\geq 2$ libraries was applied to remove lowly expressed miRNAs. MiRNAs meeting these criteria were further used in downstream analyses including differential expression (DE) analysis.

\subsection{Differential miRNA Expression}

DeSeq2 (v1.14.1) (https://bioconductor.org/packages/release/bioc/html/DESeq2.html) [28], which implements a negative binomial model, was used to perform differential miRNA expression analysis. Following normalization, normalized counts of miRNAs at D96 were compared with corresponding values on D33. Significant differential miRNA expression between D33 (pre-weaning) and D96 (post-weaning) was defined as having a Benjamini and Hochberg [29] false discovery rate (FDR) or corrected $p$-value $<0.05$. 


\subsection{Predicted Target Genes of miRNAs}

In order to investigate the functions of the most highly expressed miRNAs and differently expressed (DE) miRNAs, we firstly predicted their target mRNAs. Perl scripts (targetscan_60.pl and targetscan_61_context_scores.pl) (http:/ / targetscan.org) were used to predict target mRNAs and to calculate their context scores, respectively. Predicted target mRNAs with context + scores above 95th percentile were further used $[9,10,30]$. The predicted target mRNAs were then filtered against the mRNA transcriptome obtained from ileum tissues of the same animals. Only predicted target genes that were expressed in the mRNA transcriptome of the ileum tissues of the animals [23] were retained for further analysis.

\section{8. miRNA-mRNA Co-Expression Analysis and Target Gene Enrichment}

For miRNA-mRNA co-expression, the Pearson correlation coefficient between target mRNAs (retained above) and DE miRNAs were calculated. A miRNA-mRNA pair was considered co-expressed if it had a negative and significant correlation value at FDR $<0.05$. The mRNAs significantly correlated with miRNAs were then used for downstream target gene ontology and KEGG pathways enrichment using ClueGO (http:/ / apps.cytoscape.org/apps/cluego) [31]. For ClueGO analysis, a hypergeometric test was used for enrichment analyses and Benjamini-Hochberg [29] correction was used for multiple testing correction (FDR < 0.05). Since KEGG pathways enrichment relied on the human database (due to lack of information in bovine), we used a less stringent threshold (uncorrected $p$-value $<0.05$ ) to declare if a pathway was significantly enriched. Interactions between miRNAs and mRNAs were visualized with Cytoscape (http:/ / www.cytoscape.org/) [32].

\subsection{Real-Time Quantitative PCR}

The method of real-time quantitative PCR was used to validate the expression of four DE (bta-miR-142-5p, miR-146a, miR-24-3p and miR-374b) and two non-DE (bta-miR-486-5p and miR-193b) miRNAs. The same total RNA used in miRNA-sequencing was used. Total RNA was reverse transcribed with Universal cDNA Synthesis Kit II from Exiqon (Exiqon Inc., Woburn, MA, USA), following the manufacturer's instructions. ExiLENT SYBR ${ }^{\circledR}$ Green Master Mix Kit (Exiqon, Woburn, MA, USA) and the miRCURY LNA ${ }^{\mathrm{TM}}$ Assay (Exiqon, Woburn, MA, USA) specific for each miRNA listed above were used to perform Quantitative qPCR on a StepOne Plus System (Applied Biosystems, Foster City, CA, USA) according to the manufacturer's instructions. Bta-miR-126-3p was used as endogenous control to assess the expression level of miRNAs using the comparative $\mathrm{Ct}(\Delta \Delta \mathrm{Ct})$ method. Bta-miR-126-3p was selected as an endogenous control based on its consistent expression throughout all the analyzed samples on D33 and D96.

\section{Results}

\subsection{Identification and Characterization of Ileum miRNAs}

MiRNA sequencing of 16 libraries generated a total of 185,458,022 reads. After adaptor trimming, size selection and quality filtering, 150,999,506 (81.4\%) reads with length ranging from 18 to 30 nucleotides and having a phred score $>20$ were retained for analysis (Table S1). Out of this number, 133,698,161 reads (88.5\%) mapped to unique positions on the bovine genome (University of Maryland assembly of B. taurus, release 3.1; UMD.3.1), 10,661,520 (7.1\%) were unmapped, while 1,150,263 (0.8\%) mapped to more than five positions and were discarded (Table S1). Mapped reads belonging to other RNA species, tRNA (3,153,316 (2.1\%)), rRNA $(480,099(0.3 \%))$, snRNA $(236,118$ $(0.2 \%))$ and snoRNA $(1,620,029(1.1 \%))$ were discarded. The majority of miRNAs retained for further analyses were 22 nucleotides long (Table S2).

Novel miRNAs were considered to have a minimum MiRDeep2 score of five, as shown in Table S3. After removing lowly expressed reads, a total of 307 known and 81 novel miRNAs satisfying the 
conditions of having at least 10 read counts per million and present in a minimum of two libraries were used for DE analysis (Table S4a,b).

Abundantly expressed miRNAs having $>3 \%$ of the total read counts on D33 and D96 were bta-miR-143, bta-miR-192, bta-miR-26a and bta-miR-21-5p, while bta-miR-191, bta-miR-10b, bta-miR-148a and bta-miR-10a were highly expressed with $>3 \%$ of total read counts on D96 (post-weaning) only (Table 1). The 20 commonly highly expressed miRNAs ( $>1 \%$ of total read counts) targeted 2609 unique genes (Tables 1 and S5a). The target genes were significantly enriched in 459 biological processes (BP), 53 cellular components (CC) and 43 molecular function (MF) gene ontology (GO) terms (Table S5b), as well as in 14 KEGG pathways (Table S5c). Single-organism developmental process $\left(\mathrm{FDR}=1.13 \times 10^{-10}\right)$, intracellular $\left(\mathrm{FDR}=4.63 \times 10^{-17}\right)$, and protein binding $\left(\mathrm{FDR}=1.10 \times 10^{-5}\right)$ were the most significantly enriched BP, CC and MF GO terms, respectively (Table 2), while MAPK signaling pathway was the most significantly enriched KEGG pathway (Table 3). Moreover, a novel miRNA, bta-miR-22-24033, was the most highly expressed among novel miRNAs (accounted for $0.3 \%$ of total read counts) (Table S4b).

Table 1. The 20 most abundantly expressed miRNAs in ileum tissue of calves.

\begin{tabular}{|c|c|c|c|c|c|c|}
\hline \multirow[t]{2}{*}{ miRNA } & \multicolumn{2}{|c|}{ Pre-Weaning (D33) } & \multicolumn{2}{|c|}{ Post-Weaning (D96) } & \multicolumn{2}{|c|}{ Both Periods } \\
\hline & $\begin{array}{l}\text { Read } \\
\text { Counts }\end{array}$ & $\%$ of Total & $\begin{array}{l}\text { Read } \\
\text { Counts }\end{array}$ & $\%$ of Total & $\begin{array}{c}\text { Read } \\
\text { Counts }\end{array}$ & $\%$ of Total \\
\hline bta-miR-143 & $16,742,092$ & 24.51 & $7,468,034$ & 13.65 & $24,210,126$ & 19.68 \\
\hline bta-miR-192 & $4,435,941$ & 6.50 & $5,383,934$ & 9.84 & $9,819,875$ & 7.98 \\
\hline bta-miR-26a & $2,861,953$ & 4.19 & $4,861,644$ & 8.89 & $7,723,597$ & 6.28 \\
\hline bta-miR-191 & $1,691,133$ & 2.48 & $4,106,915$ & 7.51 & $5,798,048$ & 4.71 \\
\hline bta-miR-10b & $1,693,467$ & 2.48 & $2,031,077$ & 3.71 & $3,724,544$ & 3.03 \\
\hline bta-miR-148a & $1,702,572$ & 2.49 & $1,754,282$ & 3.21 & $3,456,854$ & 2.81 \\
\hline bta-miR-10a & $1,413,716$ & 2.07 & $1,734,580$ & 3.17 & $3,148,296$ & 2.56 \\
\hline bta-miR-21-5p & $4,233,604$ & 6.20 & $1,673,008$ & 3.06 & $5,906,612$ & 4.80 \\
\hline bta-miR-99a-5p & $1,282,425$ & 1.88 & $1,452,116$ & 2.65 & $2,734,541$ & 2.22 \\
\hline bta-miR-215 & $1,320,560$ & 1.93 & $1,373,575$ & 2.51 & $2,694,135$ & 2.19 \\
\hline bta-miR-27b & $1,557,472$ & 2.28 & $1,310,625$ & 2.40 & $2,868,097$ & 2.33 \\
\hline bta-let-7a-5p & $1,729,397$ & 2.53 & $1,231,252$ & 2.25 & $2,960,649$ & 2.41 \\
\hline bta-let-7f & $1,668,877$ & 2.44 & $1,226,489$ & 2.24 & $2,895,366$ & 2.35 \\
\hline bta-miR-125b & 923,543 & 1.35 & 987,775 & 1.81 & $1,911,318$ & 1.55 \\
\hline bta-miR-145 & $1,152,495$ & 1.69 & 798,715 & 1.46 & $1,951,210$ & 1.59 \\
\hline bta-miR-30e-5p & 699,838 & 1.02 & 735,220 & 1.34 & $1,435,058$ & 1.17 \\
\hline bta-let-7g & $1,083,909$ & 1.59 & 685,389 & 1.25 & $1,769,298$ & 1.44 \\
\hline bta-miR-194 & $1,498,650$ & 2.19 & 571,343 & 1.04 & $2,069,993$ & 1.68 \\
\hline bta-miR-30d & 747,419 & 1.09 & 560,435 & 1.02 & $1,307,854$ & 1.06 \\
\hline
\end{tabular}


Table 2. Enriched gene ontology (GO) terms for target genes of 20 most abundantly expressed miRNAs.

\begin{tabular}{|c|c|c|c|c|}
\hline GO Class & GOID & GO Term & $p$-Value & FDR \\
\hline \multirow[t]{9}{*}{ Biological process } & GO:0044767 & Single-organism developmental process & $4.40 \times 10^{-13}$ & $1.13 \times 10^{-10}$ \\
\hline & GO:0044260 & Cellular macromolecule metabolic process & $7.96 \times 10^{-13}$ & $1.79 \times 10^{-10}$ \\
\hline & GO:0044237 & Cellular metabolic process & $3.29 \times 10^{-12}$ & $6.57 \times 10^{-10}$ \\
\hline & GO:0007275 & Multicellular organismal development & $2.62 \times 10^{-11}$ & $4.71 \times 10^{-9}$ \\
\hline & GO:0048731 & System development & $7.45 \times 10^{-11}$ & $1.22 \times 10^{-8}$ \\
\hline & GO:0009888 & Tissue development & $9.21 \times 10^{-11}$ & $1.38 \times 10^{-8}$ \\
\hline & GO:0048856 & Anatomical structure development & $1.24 \times 10^{-10}$ & $1.72 \times 10^{-8}$ \\
\hline & GO:0036211 & Protein modification process & $8.55 \times 10^{-10}$ & $9.61 \times 10^{-8}$ \\
\hline & GO:0030154 & Cell differentiation & $1.74 \times 10^{-9}$ & $1.74 \times 10^{-7}$ \\
\hline \multirow[t]{11}{*}{ Cellular component } & GO:0043412 & Macromolecule modification & $3.53 \times 10^{-9}$ & $3.34 \times 10^{-7}$ \\
\hline & GO:0005622 & Intracellular & $2.57 \times 10^{-20}$ & $4.63 \times 10^{-17}$ \\
\hline & GO:0044424 & Intracellular part & $1.35 \times 10^{-19}$ & $1.22 \times 10^{-16}$ \\
\hline & GO:0043227 & Membrane-bounded organelle & $3.43 \times 10^{-17}$ & $2.06 \times 10^{-14}$ \\
\hline & GO:0043231 & Intracellular membrane-bounded organelle & $1.95 \times 10^{-15}$ & $8.79 \times 10^{-13}$ \\
\hline & GO:0043229 & Intracellular organelle & $3.08 \times 10^{-15}$ & $1.11 \times 10^{-12}$ \\
\hline & GO:0005737 & Cytoplasm & $4.55 \times 10^{-15}$ & $1.36 \times 10^{-12}$ \\
\hline & GO:0044422 & Organelle part & $2.39 \times 10^{-10}$ & $3.07 \times 10^{-8}$ \\
\hline & GO:0044446 & Intracellular organelle part & $3.80 \times 10^{-10}$ & $4.56 \times 10^{-8}$ \\
\hline & GO:0044444 & Cytoplasmic part & $9.28 \times 10^{-10}$ & $9.83 \times 10^{-8}$ \\
\hline & GO:0005634 & Nucleus & $7.71 \times 10^{-8}$ & $4.34 \times 10^{-6}$ \\
\hline \multirow[t]{9}{*}{ Molecular function } & GO:0005515 & Protein binding & $3.18 \times 10^{-7}$ & $1.10 \times 10^{-5}$ \\
\hline & GO:0019207 & Kinase regulator activity & $4.91 \times 10^{-6}$ & $1.08 \times 10^{-4}$ \\
\hline & GO:0019887 & Protein kinase regulator activity & $3.01 \times 10^{-5}$ & $4.79 \times 10^{-4}$ \\
\hline & GO:0003723 & RNA binding & $3.24 \times 10^{-5}$ & $5.06 \times 10^{-4}$ \\
\hline & GO:0019210 & Kinase inhibitor activity & $3.78 \times 10^{-5}$ & $5.76 \times 10^{-4}$ \\
\hline & GO:0004702 & $\begin{array}{l}\text { Receptor signaling protein } \\
\text { serine/threonine kinase activity }\end{array}$ & $8.23 \times 10^{-5}$ & $1.06 \times 10^{-3}$ \\
\hline & GO:0005057 & Receptor signaling protein activity & $1.94 \times 10^{-4}$ & $2.02 \times 10^{-3}$ \\
\hline & GO:0061650 & $\begin{array}{l}\text { Ubiquitin-like protein conjugating } \\
\text { enzyme activity }\end{array}$ & $3.20 \times 10^{-4}$ & $2.96 \times 10^{-3}$ \\
\hline & GO:0003700 & $\begin{array}{l}\text { Transcription factor activity, } \\
\text { sequence-specific DNA binding }\end{array}$ & $4.99 \times 10^{-4}$ & $4.17 \times 10^{-3}$ \\
\hline
\end{tabular}

Table 3. Enriched KEGG pathways for target genes of 20 most abundantly expressed miRNAs.

\begin{tabular}{ccc}
\hline KEGG Pathway & $p$-Value & FDR \\
\hline Cysteine and methionine metabolism & $2.56 \times 10^{-3}$ & $4.39 \times 10^{-2}$ \\
Amino sugar and nucleotide sugar metabolism & $1.73 \times 10^{-3}$ & $3.47 \times 10^{-2}$ \\
TGF-beta signaling pathway & $9.58 \times 10^{-4}$ & $2.30 \times 10^{-2}$ \\
Signaling pathways regulating pluripotency of stem cells & $6.67 \times 10^{-4}$ & $2.00 \times 10^{-2}$ \\
Pathways in cancer & $3.81 \times 10^{-5}$ & $4.57 \times 10^{-3}$ \\
Transcriptional misregulation in cancer & $1.76 \times 10^{-3}$ & $3.26 \times 10^{-2}$ \\
Proteoglycans in cancer & $1.39 \times 10^{-4}$ & $8.37 \times 10^{-3}$ \\
MAPK signaling pathway & $1.22 \times 10^{-5}$ & $2.94 \times 10^{-3}$ \\
Cell cycle & $3.48 \times 10^{-4}$ & $1.67 \times 10^{-2}$ \\
p53 signaling pathway & $9.32 \times 10^{-4}$ & $2.49 \times 10^{-2}$ \\
ErbB signaling pathway & $1.29 \times 10^{-3}$ & $2.81 \times 10^{-2}$ \\
FoxO signaling pathway & $5.55 \times 10^{-4}$ & $1.90 \times 10^{-2}$ \\
Chronic myeloid leukemia & $1.04 \times 10^{-4}$ & $8.35 \times 10^{-3}$ \\
Protein procesing in endoplasmic reticulum & $5.21 \times 10^{-4}$ & $2.08 \times 10^{-2}$ \\
\hline
\end{tabular}

\subsection{Differentially Expressed miRNAs and Downstream Target Gene Enrichment Analyses}

A total of 220 miRNAs (104 up-regulated and 116 down-regulated) were significantly DE between D33 (pre-weaning) and D96 (post-weaning) (Figure 1, Table S6a). Bta-miR-374a (FDR $=5.00 \times 10^{29}$ ), bta-miR-15b $\left(\mathrm{FDR}=7.96 \times 10^{24}\right)$ and bta-miR-26a $\left(\mathrm{FDR}=1.30 \times 10^{20}\right)$ were the most significantly down-regulated miRNAs, while bta-miR-455-5p $\left(\right.$ FDR $\left.=1.01 \times 10^{23}\right)$, bta-miR-210 $\left(\right.$ FDR $\left.=4.23 \times 10^{20}\right)$ and bta-miR-497 $\left(\right.$ FDR $\left.=9.95 \times 10^{20}\right)$ were the most significantly up-regulated miRNAs (Table 4$)$. 


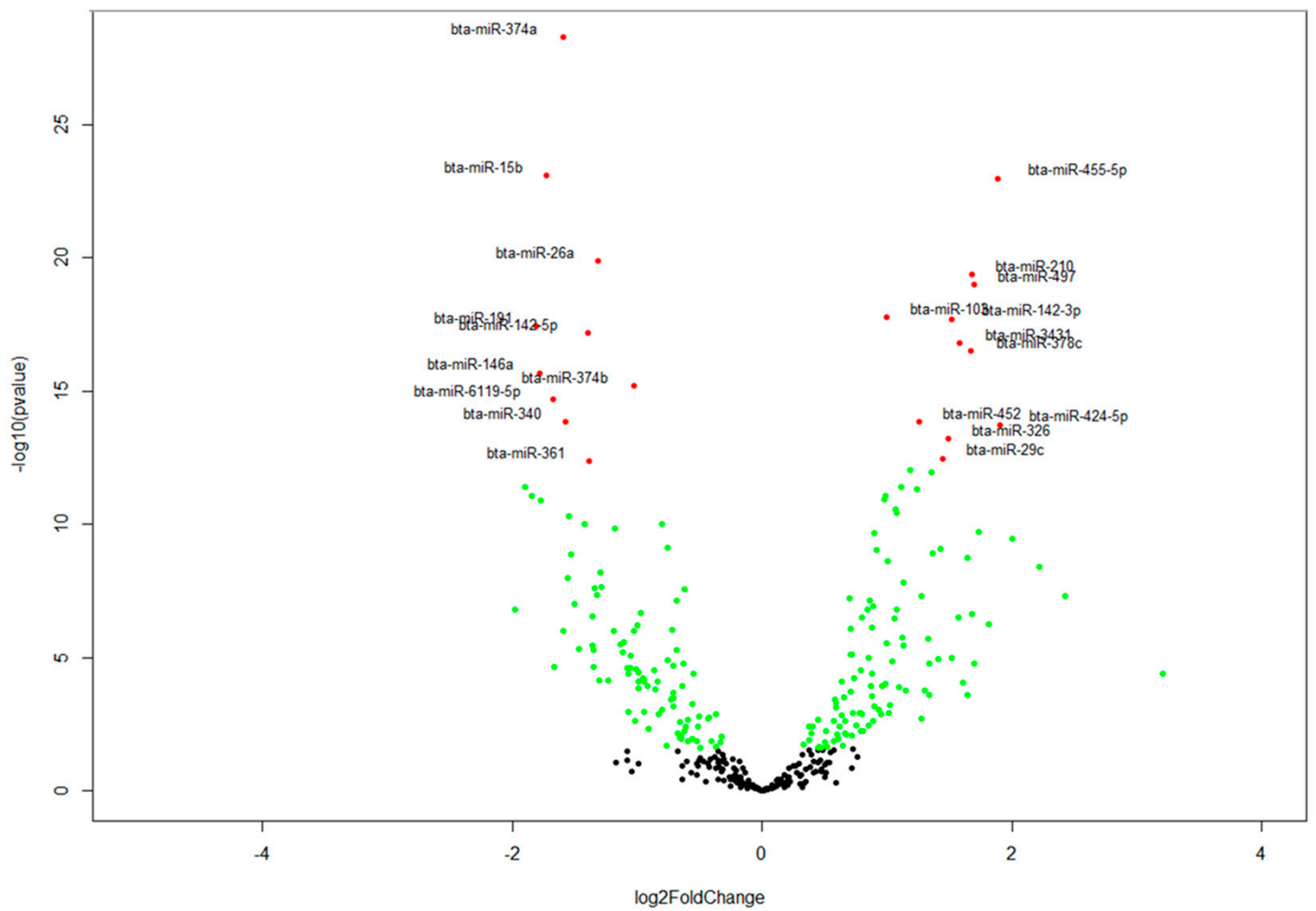

Figure 1. Volcano plot depicting miRNA differential expression results. Each dot represents a miRNA. Green and red dots represent miRNAs significantly differentially expressed at FDR $<0.05$ and FDR $<1 \times 10^{11}$, respectively. Black dots represent miRNAs that were not differentially expressed. Differential expression analysis was accomplished with DeSeq2.

Table 4. The ten most up- and down-regulated miRNAs between D33 (pre-weaning) and D96 (post-weaning).

\begin{tabular}{cccccc}
\hline miRNA & Base Mean & $\begin{array}{c}\text { Log2fold } \\
\text { Change }\end{array}$ & $\begin{array}{c}\text { Fold } \\
\text { Change }\end{array}$ & $p$-Value & FDR \\
\hline bta-miR-374a & 8851.83 & -1.59 & -3.01 & $5.00 \times 10^{-29}$ & $1.94 \times 10^{-26}$ \\
bta-miR-15b & $17,755.36$ & -1.73 & -3.32 & $7.96 \times 10^{-24}$ & $1.31 \times 10^{-21}$ \\
bta-miR-26a & $494,446.71$ & -1.32 & -2.50 & $1.30 \times 10^{-20}$ & $1.26 \times 10^{-18}$ \\
bta-miR-191 & $367,869.82$ & -1.81 & -3.51 & $3.59 \times 10^{-18}$ & $1.55 \times 10^{-16}$ \\
bta-miR-142-5p & $92,116.08$ & -1.40 & -2.64 & $6.64 \times 10^{-18}$ & $2.58 \times 10^{-16}$ \\
bta-miR-146a & $73,690.12$ & -1.79 & -3.45 & $2.04 \times 10^{-16}$ & $6.08 \times 10^{-15}$ \\
bta-miR-374b & 4629.32 & -1.03 & -2.04 & $6.14 \times 10^{-16}$ & $1.70 \times 10^{-14}$ \\
bta-miR-6119-5p & 1796.83 & -1.68 & -3.19 & $2.08 \times 10^{-15}$ & $5.38 \times 10^{-14}$ \\
bta-miR-340 & 360.85 & -1.58 & -2.99 & $1.40 \times 10^{-14}$ & $3.31 \times 10^{-13}$ \\
bta-miR-361 & 9880.75 & -1.39 & -2.62 & $4.33 \times 10^{-13}$ & $8.00 \times 10^{-12}$ \\
bta-miR-455-5p & 282.27 & 1.89 & 3.70 & $1.01 \times 10^{-23}$ & $1.31 \times 10^{-21}$ \\
bta-miR-210 & 486.48 & 1.67 & 3.19 & $4.23 \times 10^{-20}$ & $3.28 \times 10^{-18}$ \\
bta-miR-497 & 692.69 & 1.70 & 3.24 & $9.95 \times 10^{-20}$ & $6.43 \times 10^{-18}$ \\
bta-miR-103 & $39,682.96$ & 1.00 & 2.00 & $1.69 \times 10^{-18}$ & $9.35 \times 10^{-17}$ \\
bta-miR-142-3p & 1742.08 & 1.52 & 2.87 & $1.96 \times 10^{-18}$ & $9.52 \times 10^{-17}$ \\
bta-miR-3431 & 614.77 & 1.58 & 2.98 & $1.58 \times 10^{-17}$ & $5.57 \times 10^{-16}$ \\
bta-miR-378c & 1268.42 & 1.67 & 3.18 & $3.21 \times 10^{-17}$ & $1.04 \times 10^{-15}$ \\
bta-miR-452 & 393.30 & 1.26 & 2.39 & $1.45 \times 10^{-14}$ & $3.31 \times 10^{-13}$ \\
bta-miR-424-5p & 301.96 & 1.90 & 3.73 & $1.84 \times 10^{-14}$ & $3.97 \times 10^{-13}$ \\
bta-miR-326 & 378.11 & 1.49 & 2.82 & $6.07 \times 10^{-14}$ & $1.24 \times 10^{-12}$ \\
\hline
\end{tabular}


The DE miRNAs (220 miRNAs) were predicted to target 11,691 mRNAs (Table S6b). Using mRNA transcriptome data of the same samples, 1560 mRNAs out of the predicted 11,691 mRNAs, were significantly and negatively correlated with their targeting miRNAs (Table S6c). Bta-miR-2285f had the highest number of target genes (172), while $A G O 2$ gene was the most popular target for DE miRNAs (targeted by 25 DE miRNAs) (Table S6c). Other common target genes for DE miRNAs were SLC25A46, KCTD13 and PAXIP1, each targeted by 9 DE miRNAs (Table S6c). The GO enrichment analyses of the 1560 target genes (significantly and negatively correlated with miRNA) indicated that 158, 26 and 28 of them were significantly enriched in BP-, CC- and MF-GO terms, respectively (Table S7a-c). The most enriched BP-, CC- and MF-GO terms were cellular macromolecule metabolic process $\left(\mathrm{FDR}=9.38 \times 10^{10}\right)$, intracellular $\left(\mathrm{FDR}=3.37 \times 10^{19}\right)$ and organic cyclic compound binding $\left(\right.$ FDR $\left.=1.19 \times 10^{4}\right)$, respectively (Table 5, Figures 2-4). Moreover, 16 KEGG pathways were significantly enriched for the target genes (1560) of $220 \mathrm{DE}$ miRNAs, and peroxisome $(p=0.004)$ and Hedgehog signaling pathways $(p=0.006)$ were the most significantly enriched (Table S7d, Figure 5). Moreover, among the 1560 target genes negatively correlated with miRNAs, 278 were also significantly DE between D33 and D96 in our previous study (Table S8) [23]. The 278 genes were the targets for 64 DE miRNAs. SOX 4 was the most common target, since it was targeted by 6 different miRNAs (bta-miR-191, bta-miR-30e-5p, bta-miR-15-11508, bta-miR-2285f, bta-miR-92b and bta-miR-2285q). Meanwhile, bta-miR-2285f and bta-miR-874 had the highest number of target genes (37 and 28, respectively) (Figure 6).

Table 5. Most significantly enriched gene ontology (GO) terms for target genes of differentially expressed miRNAs.

\begin{tabular}{|c|c|c|c|c|}
\hline GO Class & GO ID & GO Term & $p$-Value & FDR \\
\hline \multirow{8}{*}{$\begin{array}{l}\text { Biological } \\
\text { process }\end{array}$} & GO:0044260 & Cellular macromolecule metabolic process & $9.38 \times 10^{-10}$ & $5.11 \times 10^{-7}$ \\
\hline & GO:0043170 & Macromolecule metabolic process & $6.49 \times 10^{-10}$ & $7.07 \times 10^{-7}$ \\
\hline & GO:0048518 & Positive regulation of biological process & $1.67 \times 10^{-8}$ & $4.55 \times 10^{-6}$ \\
\hline & GO:0071704 & Organic substance metabolic process & $4.25 \times 10^{-8}$ & $7.72 \times 10^{-6}$ \\
\hline & GO:0090304 & Nucleic acid metabolic process & $3.66 \times 10^{-8}$ & $7.97 \times 10^{-6}$ \\
\hline & GO:0044237 & Cellular metabolic process & $8.67 \times 10^{-8}$ & $1.35 \times 10^{-5}$ \\
\hline & GO:0009059 & Macromolecule biosynthetic process & $1.76 \times 10^{-7}$ & $1.60 \times 10^{-5}$ \\
\hline & GO:0048522 & Positive regulation of cellular process & $1.92 \times 10^{-7}$ & $1.61 \times 10^{-5}$ \\
\hline \multirow{6}{*}{$\begin{array}{l}\text { Cellular } \\
\text { component }\end{array}$} & GO:0005622 & Intracellular & $2.76 \times 10^{-21}$ & $3.37 \times 10^{-19}$ \\
\hline & GO:0043229 & Intracellular organelle & $2.39 \times 10^{-21}$ & $5.85 \times 10^{-19}$ \\
\hline & GO:0044424 & Intracellular part & $1.21 \times 10^{-20}$ & $9.85 \times 10^{-19}$ \\
\hline & GO:0005737 & Cytoplasm & $1.69 \times 10^{-10}$ & $5.90 \times 10^{-9}$ \\
\hline & GO:0005654 & Nucleoplasm & $1.80 \times 10^{-9}$ & $5.52 \times 10^{-8}$ \\
\hline & GO:0044428 & Nuclear part & $4.96 \times 10^{-9}$ & $1.35 \times 10^{-7}$ \\
\hline \multirow{8}{*}{$\begin{array}{l}\text { Molecular } \\
\text { function }\end{array}$} & GO:0044446 & Intracellular organelle part & $1.06 \times 10^{-8}$ & $2.59 \times 10^{-7}$ \\
\hline & GO:0097159 & Organic cyclic compound binding & $1.19 \times 10^{-6}$ & $1.19 \times 10^{-4}$ \\
\hline & GO:1901363 & Heterocyclic compound binding & $6.87 \times 10^{-7}$ & $1.37 \times 10^{-4}$ \\
\hline & GO:0043167 & Ion binding & $2.32 \times 10^{-5}$ & $1.16 \times 10^{-3}$ \\
\hline & GO:0003676 & Nucleic acid binding & $2.03 \times 10^{-5}$ & $1.36 \times 10^{-3}$ \\
\hline & GO:0005515 & Protein binding & $3.90 \times 10^{-5}$ & $1.56 \times 10^{-3}$ \\
\hline & GO:0019207 & Kinase regulator activity & $5.59 \times 10^{-5}$ & $1.60 \times 10^{-3}$ \\
\hline & GO:0019887 & Protein kinase regulator activity & $5.31 \times 10^{-5}$ & $1.77 \times 10^{-3}$ \\
\hline
\end{tabular}




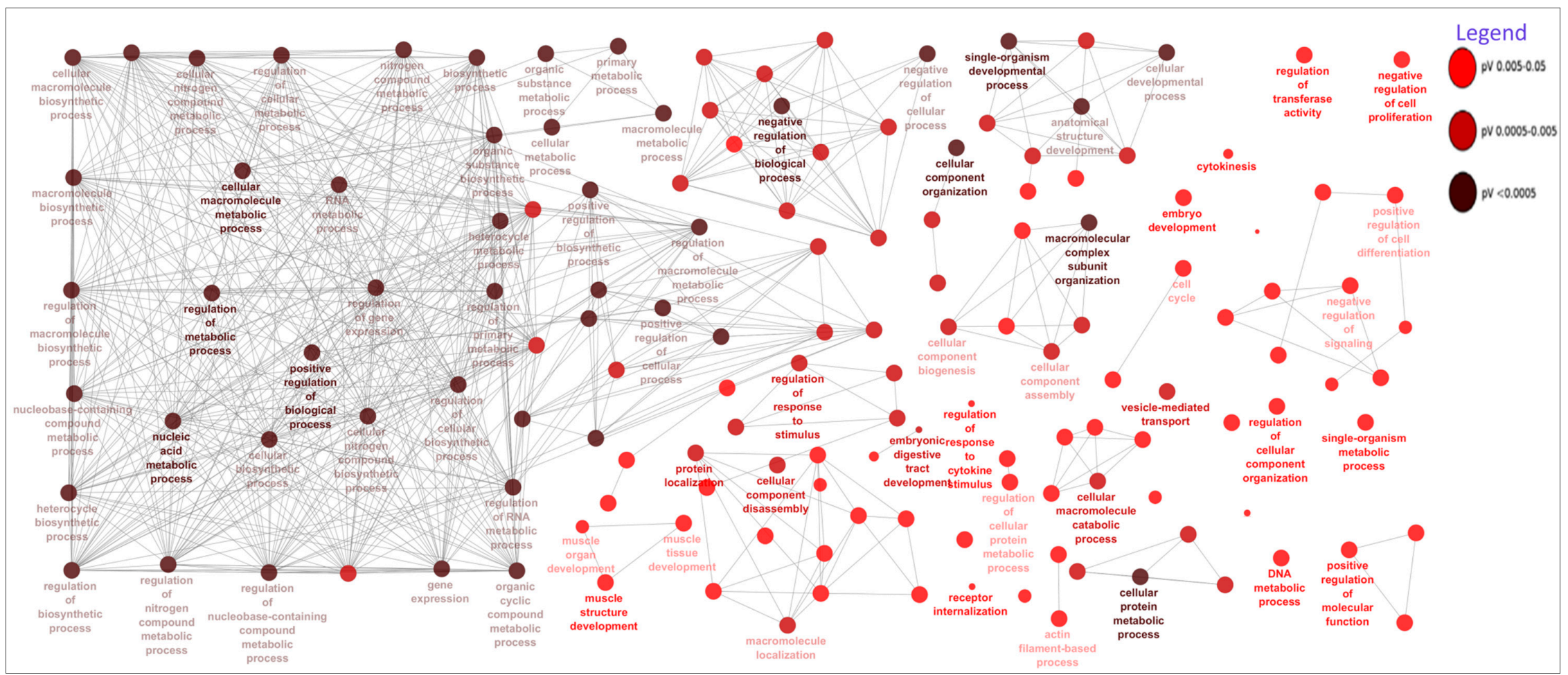

Figure 2. The ClueGO results for biological processes gene ontology terms enrichment for target genes (mRNAs) of differentially expressed miRNAs and relationships between them. The nodes (round shape) represent gene ontology terms, node color represents the level of significance as indicated in the legend, while node size reflects the number of genes enriched in each gene ontology term. 


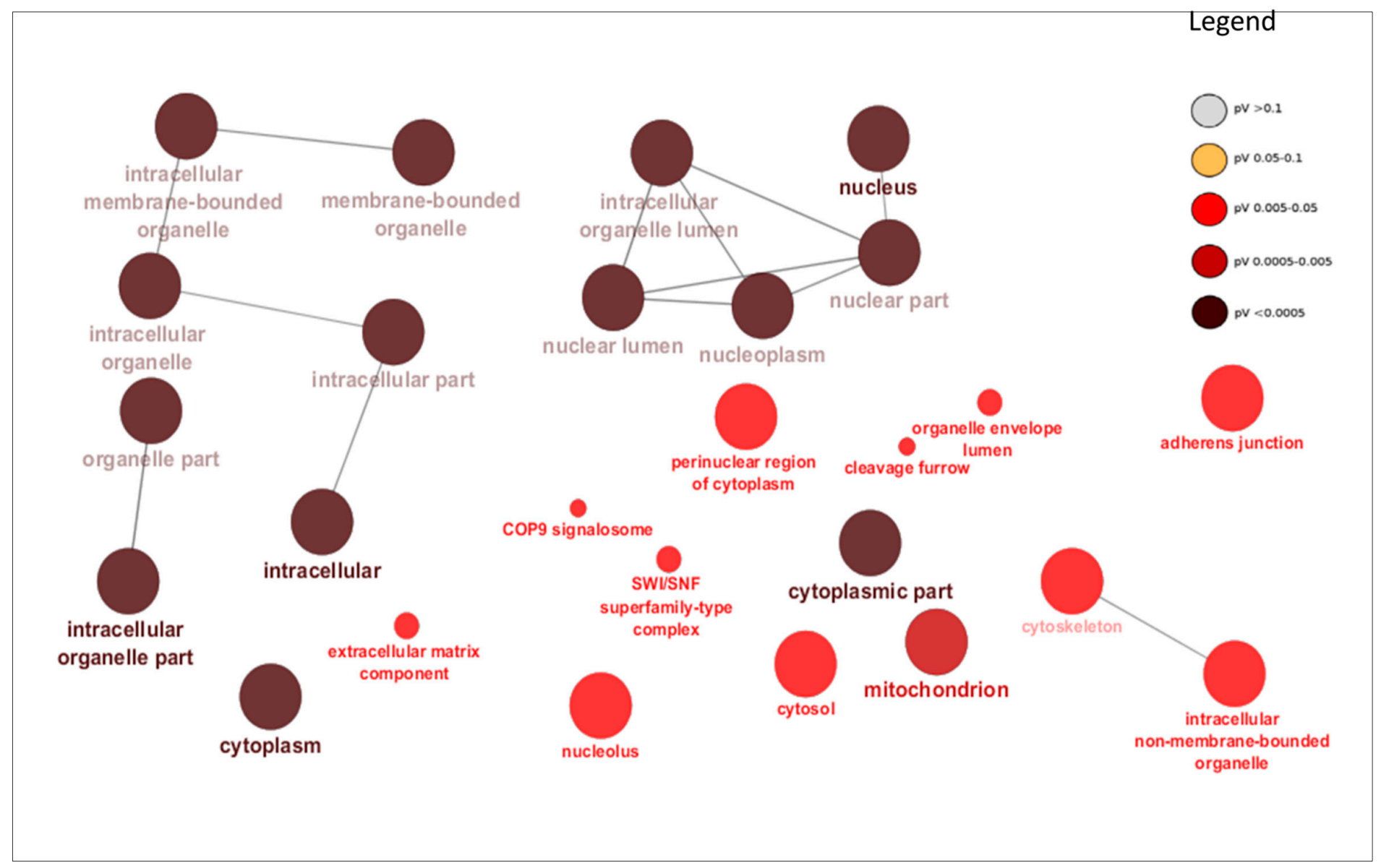

Figure 3. The ClueGO results for cellular processes gene ontology terms enrichment for target genes of differentially expressed miRNAs and relationships between them. The nodes (round shape) represent gene ontology terms, node color represents the level of significance as indicated in the legend, while node size reflects the number of genes enriched in each gene ontology term. 


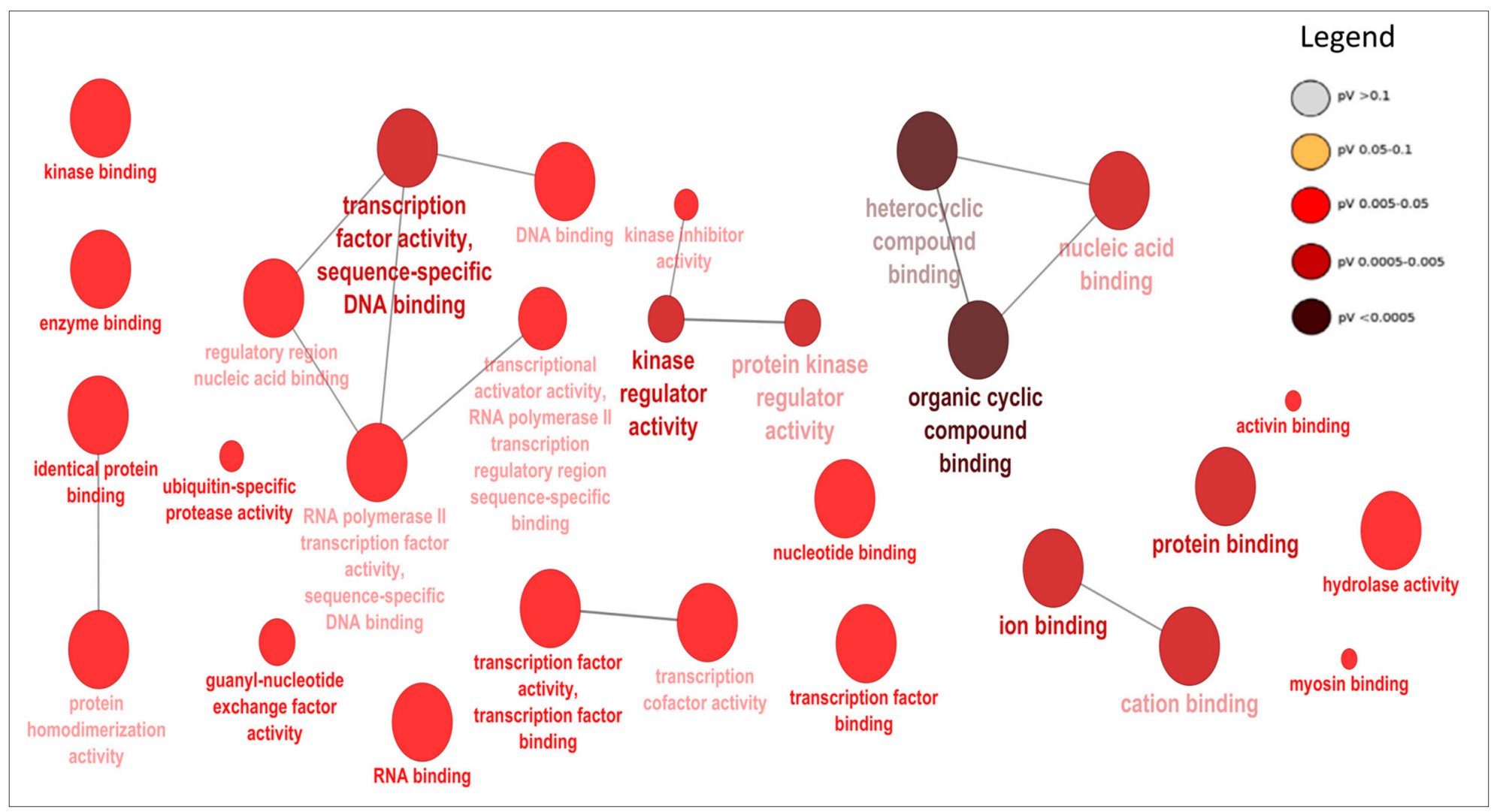

Figure 4. The ClueGO results for molecular functions gene ontology terms enrichment for target genes of differentially expressed miRNAs and relationships between them. The nodes (round shape) represent gene ontology terms, node color represents the level of significance as indicated in the legend, while node size reflects the number of genes enriched in each gene ontology term. 


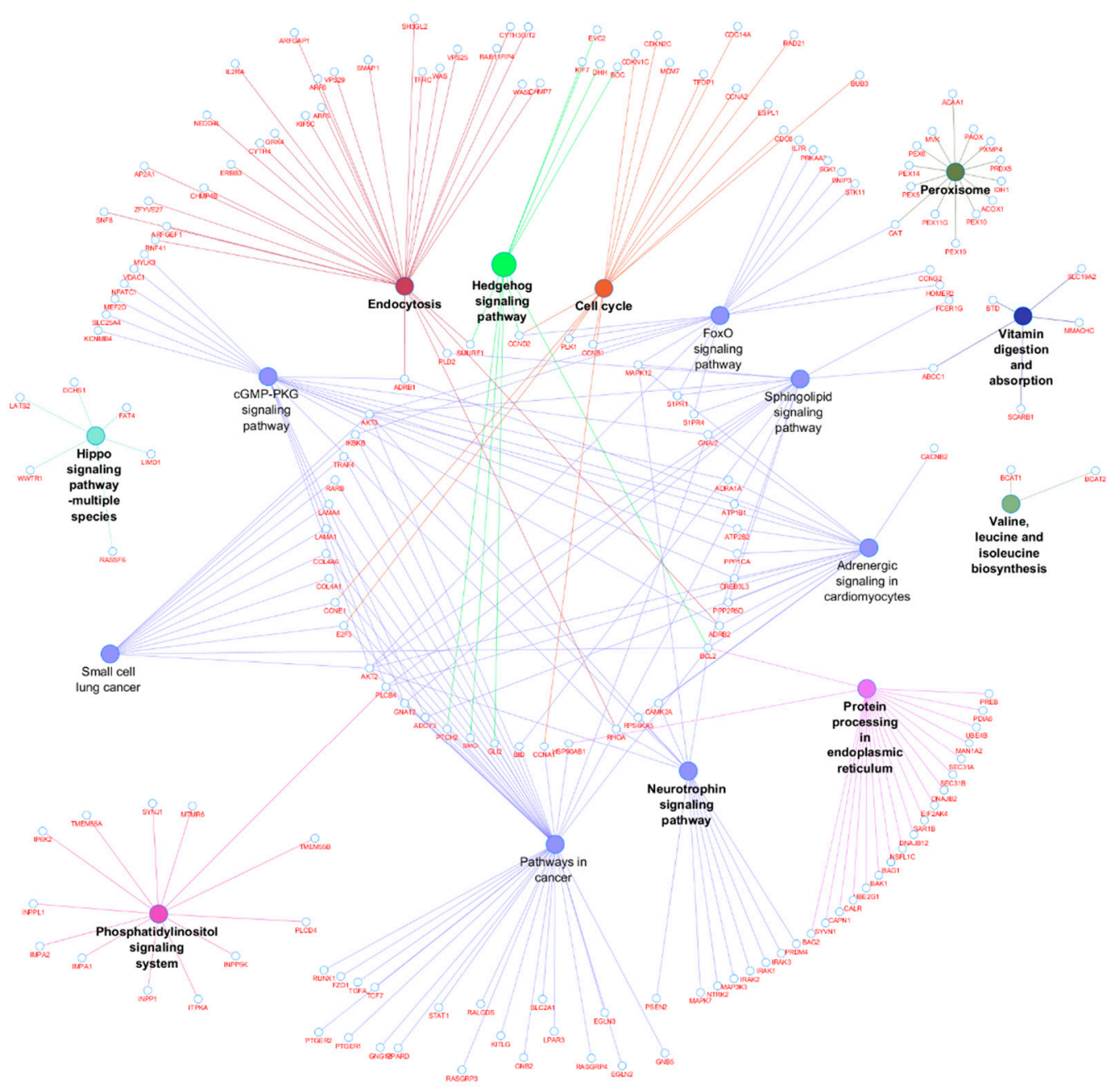

Figure 5. The ClueGO results for KEGG pathways enrichment for target genes of differentially expressed miRNAs and relationships between them. The nodes (round shapes) represent KEGG pathways or genes enriched in the pathways. 


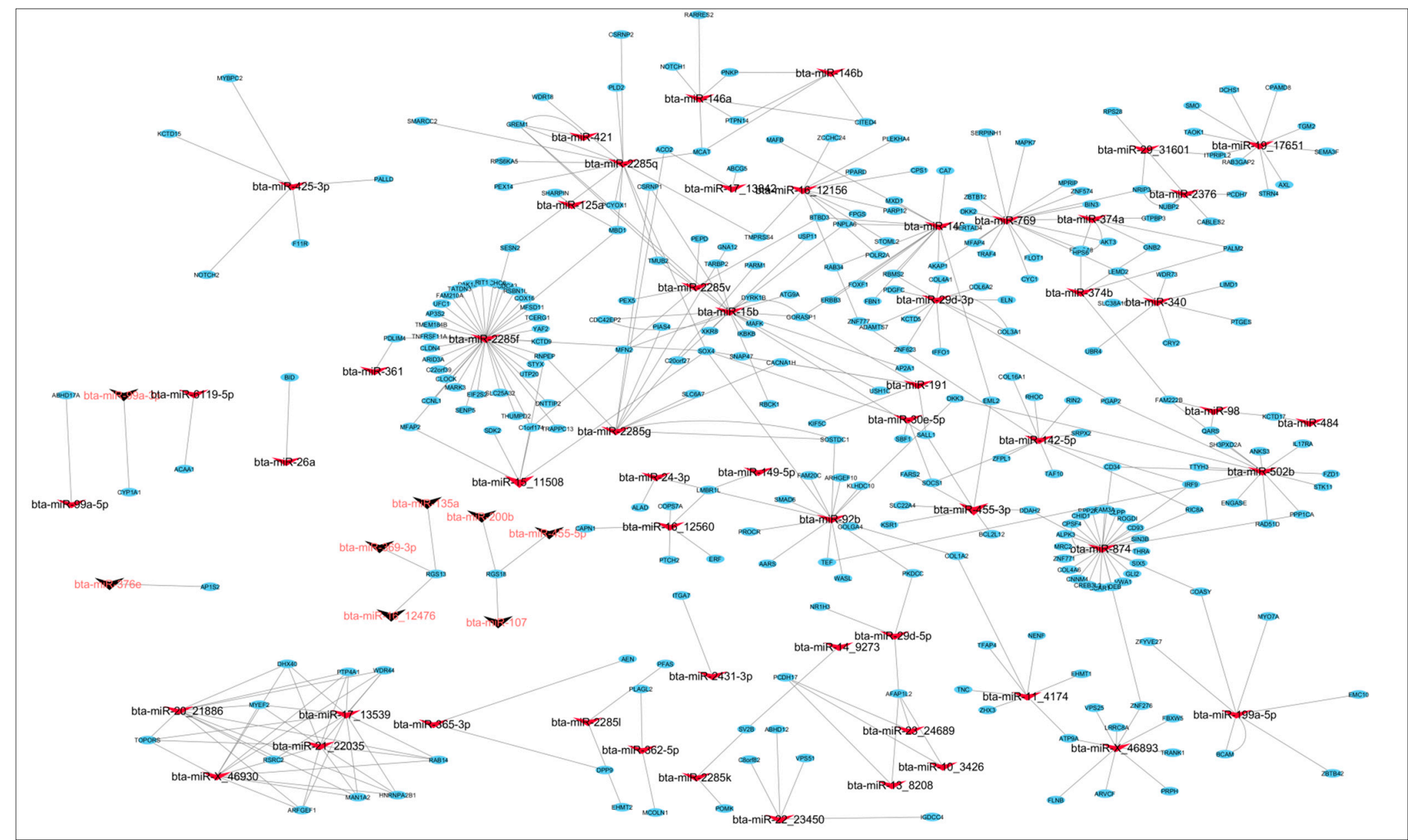

Figure 6. The Cytoscape visualization of the relationships between differentially expressed miRNAs and their target mRNAs. The nodes present either genes (round shape) or miRNAs (V shape). The up- and down-regulated miRNAs are colored red and black, respectively. 


\subsection{Real Time Quantitative PCR Validation}

The RNA-Seq expression of 6 miRNAs was validated by qPCR. Two of them (bta-miR-486-5p and bta-miR-193b) were non DE, while four of them (bta-miR-142-5p, miR-146a, miR-24-3p and miR-374b) were DE between D33 and D96 by RNA-Seq. Observed fold changes for DE miRNAs between both methods were similar, except for the non-DE miRNAs, where an opposite trend was observed (Figure 7).

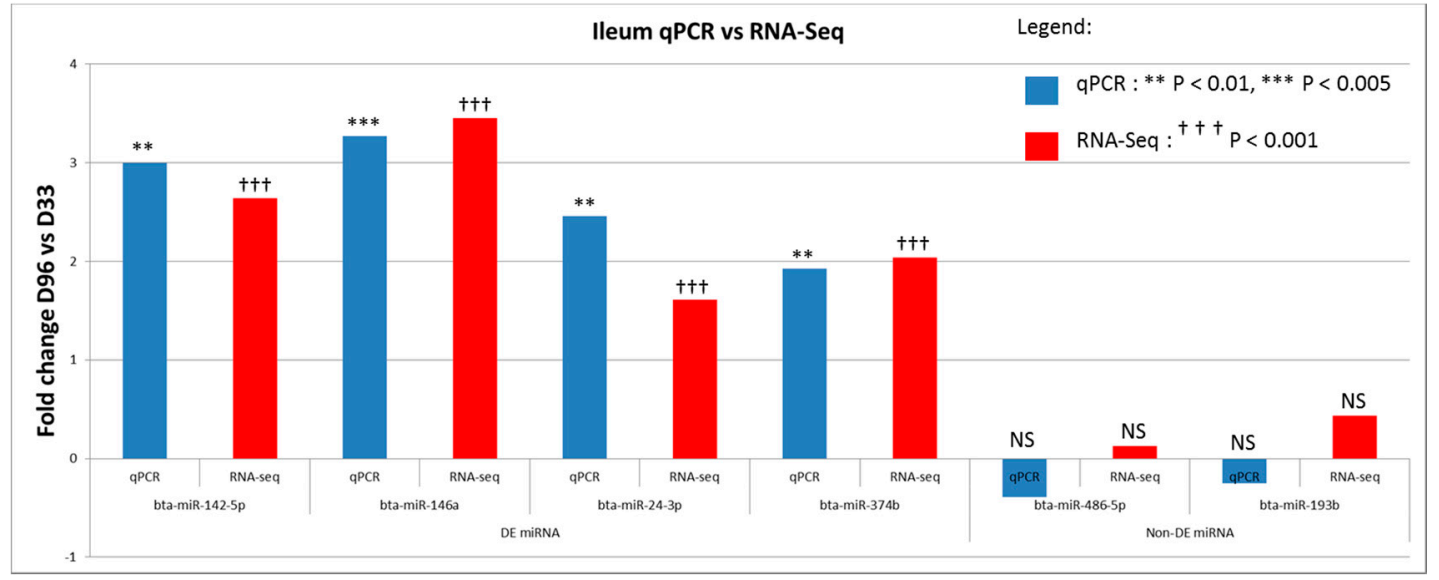

Figure 7. Result of qPCR validation of the expression of miRNAs between day 33 (pre-weaning) and day 96 (post-weaning), and compared with results obtained by miRNA sequencing.

\section{Discussion}

Physiologically, major metabolic changes that take place in calf gastrointestinal tract following the transition from liquid to solid food are accompanied by rapid changes in gene expression controlled by the signal-mediated coordination of transcriptional and post-transcriptional mechanisms [33]. Previously, we reported that $20 \%$ of bovine genes were significantly DE between the pre-weaning (day 33) and the post-weaning (day 96) period, and enrichment analysis revealed the importance of DE genes in biological processes necessary for the switch in nutrition and developmental stage from the pre-weaning to the post-weaning period [23]. While it is well known that miRNAs are important for the regulation of these processes, little is known about how they participate in the regulation of ileum functions from the pre-weaning to the post-weaning period.

Highly expressed and DE miRNAs identified in this study suggest potential roles in ileum developmental processes during the transition from the pre-weaning to the post-weaning period. However, some highly expressed miRNAs such as bta-miR-21-5p, bta-miR-26a, bta-miR-148a and bta-let-7a-5p (Table 1) were also highly expressed in other tissues such as milk fat [10], milk whey/somatic cells [25], and mammary gland epithelial cells [13]. Interestingly, bta-miR-143, the most highly expressed miRNA, was also among the most abundant miRNAs in bovine testis [34] and reported as the most highly expressed miRNA in ileum tissue of calves at the pre- and post-weaning periods [35]. It was suggested that bta-miR-143 might regulate key genes involved in differentiation of connective tissue cells, the major components of the gut; hence, its high abundance might be important for the regulation of rapid development and growth of the gastrointestinal tract during early life. Indeed, enrichment analysis of target genes of the top 20 abundant miRNAs indicated enrichment in many biological processes and molecular function GO terms (Tables 2 and S5) involved in developmental processes, therefore supporting important roles for highly abundant miRNAs, including bta-miR-143, in these processes. Further supporting evidence was derived from enriched KEGG pathways crucial for cellular development processes such as FoxO signaling pathway, cell cycle, MAPK signaling pathway, and p53 signaling pathway (Table 3). Moreover, we also detected 81 novel miRNAs in this study that were lowly expressed. The most abundant novel miRNA, bta-miR-22_24033, 
accounted for only $0.3 \%$ of the total read counts. Forty-four novel miRNAs were significantly DE between D33 and D96, therefore suggesting roles in the regulation of ileum gene expression during the early period of growth. Nevertheless, novel miRNAs identified in this study will enrich the bovine miRNome as well as enhance knowledge of the potential roles of miRNAs in calf GIT. However, further functional validations to clarify the roles of identified miRNAs in the development of calf gut during the early period of growth are needed.

Bta-miR-374a was the most significantly DE miRNA in this study (Table 4). Bta-miR-374a was found to be differentially expressed between lactating and non-lactating cows [36]. Bta-miR-374a potentially targeted 36 different genes (Table S6b) and some of them might be important for ileum functions such as EIF2AK4, FBXO18, GTPBP3 and GNB2, etc. EIF2AK4 is an important transcription factor in host response to infection with pathogenic bacteria associated with Crohn's disease [37]. Moreover, FBXO18, GTPBP3 and GNB2 have been reported to be significantly DE in calf gastrointestinal tract between the pre- and post-weaning periods [23]. FBXO18 encodes a member of the F-box protein family with function in phosphorylation-dependent ubiquitination [38]. FBXO18 is implicated in the regulation of stress-induced apoptosis processes and homologous recombination in familial and sporadic breast cancer [39]. Cells deficient in FBXO18 were unable to activate the cytotoxic-stress-induced cascade, resulting in increased cell survival [40]. GTPBP3 is an important gene for mitochondrial functions and a mutation in this gene resulted in defective mitochondrial energy production through oxidative phosphorylation [41]. GNB2 is important for neuronal apoptosis and was induced by lidocaine in the rat [42]. Nevertheless, the functions of these genes (FBXO18, GTPBP3 and GNB2) in the ileum are unknown. Bta-miR-15b, the second most significantly up-regulated miRNA, belongs to the miR-15b family cluster. This miRNA cluster can target cell cycle proteins and the anti-apoptotic $B c l-2$ gene to control cell proliferation and apoptosis [43]. Bta-miR-15b might also play a role in mastitis disease development in cows [44]. Moreover, Liang et al. [35] also reported that bta-miR-15b was significantly DE between 0 -day-old and 7-day-old calves and its expression correlated with bacterial population, thus suggesting roles in the regulation of gut development, immune, and digestive functions. Furthermore, bta-miR-15b potentially targeted IKBKB (Figure 6), a gene known as an essential molecule for NF- $\mathrm{kB}$ signaling pathway [45] with important roles in both innate and acquired immunity [46].

Interestingly, bta-miR-26a, one of the most significantly DE miRNA (Table 4), was also one of the most highly expressed miRNA (Table 1). The human homologue of this miRNA plays important roles in Crohn's disease [15]. In cattle, this miRNA regulates the expression of PCK1 gene, which is important for semen quality and longevity of Holstein bulls [47]. Bta-miR-26a potentially targeted BID gene and their expressions were significantly correlated in this study (Figure 6). BID is a pro-apoptotic member of the Bcl-2 protein family with roles in the regulation of apoptosis processes [46]. Therefore, bta-miR-26a might have roles in ileum development via targeting the BID gene. Bta-miR-455-5p was the most down-regulated miRNA between D33 and D96. Bta-miR-455-5p was reported to be important for the function of granulosa cells of subordinate and dominant follicles during the early luteal phase of the bovine estrous cycle [48]. In humans, this miRNA homologue down regulated $R A B 18$ gene in gastric cancer [49]. In fact, bta-miR-455-5p also potentially targeted $R A B 18$ gene in this study (Figure 6).

Among the top 20 DE miRNAs in this study, bta-miR-142-3p, bta-miR-142-5p, bta-miR-191, bta-miR-146a, bta-miR-210 and bta-miR-424-5p were also found to be DE in calf ileum at the pre-weaning and weaning periods [35]. Some of these miRNAs have been reported to play important roles in immune functions. For example, bta-miR-146a inhibited the mRNA and protein expression levels of TRAF6 gene and acted as a negative feedback regulator of bovine inflammation and innate immunity through down regulation of the TLR4/TRAF6/NF- $\mathrm{kB}$ pathway in bovine mammary epithelial cells [50]. Furthermore, bta-miR-142-5p was important for bovine alveolar macrophage response to Mycobacterium bovis infection [51].

As expected, the target genes of DE miRNAs were enriched in important biological process GO-terms related to metabolic processes (such as cellular macromolecule metabolic process, 
macromolecule metabolic process and regulation of metabolic process) (Table 5 and Figure 2) and molecular function GO-terms related to metabolism of the macromolecule compound (such as organic cyclic compound binding, heterocyclic compound binding, nucleic acid binding and protein binding) (Table 5 and Figure 4), thus suggesting roles in the regulation of these processes. Interestingly, the target genes of DE miRNAs were also enriched in GO-terms like transcription factor activity and sequence-specific DNA binding $\left(\mathrm{FDR}=3.63 \times 10^{-3}\right.$ ) (Table 5), thus suggesting their importance in transcription factor activity. The interaction between miRNAs and transcription factors to regulate gene expression in biological processes is well documented [52,53]. MiRNAs might inhibit transcription factor activities by either directly inhibiting the expression of their encoding genes or by inhibiting other gene(s) that have impact on their activities [53,54]. Previously, we observed that some transcription factors might play important roles in mediating miRNA regulatory functions in cow milk yield and milk component traits [9]. In humans, several miRNAs have been reported to participate in the regulation of intestinal transcription factors; miR-196b inhibited the GATA6 intestinal transcription factor to control intestinal cell homeostasis and tumorigenesis in colon cancer patients [55], while miR-30 family controlled intestinal epithelial cell proliferation and differentiation by targeting SOX9 (transcription factor) and other genes in ubiquitin ligase pathway [56]. In fact, as mentioned above, the most DE miRNA in this study (bta-miR-374) also potentially targeted a transcription factor (EIF2AK4) known to be important for human Crohn's disease [37]. The most important pathway enriched for DE miRNAs target genes was Hedgehog signaling pathway $(p=0.003$, Table S7, Figure 5). Hedgehog signaling pathway is important for cell growth, survival and fate, as well as for normal embryonic development $[57,58]$. This pathway also has multiple patterning functions during mammalian gut development [59]; therefore, it may be important for ileum functions during the early part of life. Another important pathway enriched for target genes of DE miRNAs was peroxisomes pathway $(p=0.006$, Table S7, Figure 5). The peroxisomes pathway is crucial for metabolic processes such as fatty acid oxidation, biosynthesis of ether lipids, and free radical detoxification [60]. Since one of the main functions of the ileum is to absorb bile salts, one of the products of fatty acid oxidation, enrichment of the peroxisome pathway supports its role in normal ileum function. Another important role of the ileum is vitamin absorption and the enriched pathway, vitamin digestion and absorption (Table S7 and Figure 5), might reflect the changes in gene expression for different vitamin requirements between the pre- and post-weaning periods. Other enriched pathways also reflect the importance of miRNAs in the regulation of genes involved in lipid metabolism (phosphatidylinositol signaling system and sphingolipid signaling pathway), protein metabolism (valine, leucine and isoleucine biosynthesis and protein processing in endoplasmic reticulum) and intracellular signaling (cGMP-PKG signaling, FoxO signaling and neurotrophin signaling pathway) in the development of the ileum during the early part of life.

\section{Conclusions}

This is the first integrated miRNA-mRNA analysis characterizing the function of miRNAs in calf ileum during early life. Eighty-one novel miRNAs were identified that will enrich the bovine miRNome repertoire and contribute to the understanding of regulatory processes in calf ileum. This study highlighted potential roles of bta-miR-143, bta-miR-192, bta-miR-26a and bta-miR-21-5p in growth and developmental processes during the transition from the pre-weaning to the post-weaning period. This study also suggested roles for DE miRNAs in metabolic processes, metabolism of the macromolecule compound, transcription factor activities, as well as involvement in pathways related to metabolism (peroxisomes), vitamin digestion and absorption, lipid and protein metabolism, and intracellular signaling (Hedgehog signaling, GMP-PKG signaling, FoxO signaling, neurotrophin signaling pathway). Moreover, several DE miRNAs-DE mRNAs pairs such as bta-miR-374a-FBXO18, bta-miR-374a-GTPBP3 and bta-miR-374a-GNB2 with potential roles in tissue development, and bta-miR-15b-IKBKB with vital roles in immune functions were revealed. This study, therefore, provided insights on miRNA expression and their potential functions in calf 
ileum development during early life, which might facilitate identification of miRNA biomarkers for growth, nutritional and disease challenges during the pre- and post-weaning periods.

Supplementary Materials: The following are available online at http:/ /www.mdpi.com/2073-4409/7/9/134/s1. Table S1: Mapping statistics of miRNA sequencing reads; Table S2: Length distribution (nt) of miRNA reads; Table S3: Novel miRNAs identified by miRDeep2; Table S4: Novel and known miRNAs and their read count summary; Table S5; The 20 most highly expressed miRNAs and their predicted target genes (a); enriched gene ontology terms (b) and enriched KEGG pathways (c); Table S6; Differentially expressed miRNAs between day 33 (pre-weaning) and day 96 (post-weaning) (a); predicted target genes of DE miRNAs (b) and differentially expressed genes which are both negatively correlated and predicted targets of miRNAs (c); Table S7; Gene ontology and KEGG pathways enriched for target genes of differential expressed miRNAs; Table S8; Differentially expressed genes that were targets of DE miRNAs and also negatively correlated.

Author Contributions: Conceived and designed the experiments, E.M.I.-A.; Performed the experiments, B.E.F. and P.-L.D.; Data analysis/curation, P.-L.D. and D.N.D.; Writing-Original Draft Preparation, D.N.D.; Writing-Review \& Editing, E.M.I.-A.; Visualization, D.N.D.; Supervision and Project Administration, E.M.I.-A.; Funding Acquisition, E.M.I.-A.; all authors revised and approved the final draft.

Funding: This work was supported by funding from Agriculture and Agri-Food Canada to Eveline M. Ibeagha-Awemu, grant number J-000218.

Acknowledgments: Authors thank farm staff of Agriculture and Agri-Food Canada's Sherbrooke Research and Development Center for assistance in animal management.

Conflicts of Interest: The authors declare no conflict of interest.

\section{References}

1. Ambros, V. The functions of animal micrornas. Nature 2004, 431, 350-355. [CrossRef] [PubMed]

2. Carthew, R.W.; Sontheimer, E.J. Origins and mechanisms of miRNAs and siRNAs. Cell 2009, 136, $642-655$. [CrossRef] [PubMed]

3. Coutinho, L.L.; Matukumalli, L.K.; Sonstegard, T.S.; Van Tassell, C.P.; Gasbarre, L.C.; Capuco, A.V.; Smith, T.P. Discovery and profiling of bovine micrornas from immune-related and embryonic tissues. Physiol. Genet. 2007, 29, 35-43. [CrossRef] [PubMed]

4. Ponsuksili, S.; Tesfaye, D.; Schellander, K.; Hoelker, M.; Hadlich, F.; Schwerin, M.; Wimmers, K. Differential expression of mirnas and their target mRNAs in endometria prior to maternal recognition of pregnancy associates with endometrial receptivity for in vivo-and in vitro-produced bovine embryos. Biol. Reprod. 2014, 91, 1-12. [CrossRef] [PubMed]

5. Hossain, M.; Salilew-Wondim, D.; Schellander, K.; Tesfaye, D. The role of micrornas in mammalian oocytes and embryos. Anim. Reprod. Sci. 2012, 134, 36-44. [CrossRef] [PubMed]

6. Do, D.N.; Ibeagha-Awemu, E.M. Non-coding RNA roles in ruminant mammary gland development and lactation. In Current Topics in Lactation; InTech: Rijeka, Croatia, 2017.

7. Gu, Z.; Eleswarapu, S.; Jiang, H. Identification and characterization of micrornas from the bovine adipose tissue and mammary gland. FEBS Lett. 2007, 581, 981-988. [CrossRef] [PubMed]

8. Jin, W.; Dodson, M.V.; Moore, S.S.; Basarab, J.A. Characterization of microrna expression in bovine adipose tissues: A potential regulatory mechanism of subcutaneous adipose tissue development. BMC Mol. Biol. 2010, 11, 29. [CrossRef] [PubMed]

9. Do, D.N.; Dudemaine, P.-L.; Li, R.; Ibeagha-Awemu, E.M. Co-expression network and pathway analyses reveal important modules of mirnas regulating milk yield and component traits. Int. J. Mol. Sci. 2017, 18, 1560. [CrossRef] [PubMed]

10. Do, D.N.; Li, R.; Dudemaine, P.-L.; Ibeagha-Awemu, E.M. Microrna roles in signalling during lactation: An insight from differential expression, time course and pathway analyses of deep sequence data. Sci. Rep. 2017, 7. [CrossRef] [PubMed]

11. Jabed, A.; Wagner, S.; McCracken, J.; Wells, D.N.; Laible, G. Targeted microrna expression in dairy cattle directs production of $\beta$-lactoglobulin-free, high-casein milk. Proc. Natl. Acad. Sci. USA 2012, 109, 16811-16816. [CrossRef] [PubMed]

12. Naeem, A.; Zhong, K.; Moisá, S.; Drackley, J.; Moyes, K.; Loor, J. Bioinformatics analysis of microRNA and putative target genes in bovine mammary tissue infected with streptococcus uberis. J. Dairy Sci. 2012, 95, 6397-6408. [CrossRef] [PubMed] 
13. Jin, W.; Ibeagha-Awemu, E.M.; Liang, G.; Beaudoin, F.; Zhao, X.; Guan, L.L. Transcriptome microrna profiling of bovine mammary epithelial cells challenged with Escherichia coli or staphylococcus aureusbacteria reveals pathogen directed microRNA expression profiles. BMC Genet. 2014, 15, 181.

14. Farrell, D.; Shaughnessy, R.G.; Britton, L.; MacHugh, D.E.; Markey, B.; Gordon, S.V. The identification of circulating mirna in bovine serum and their potential as novel biomarkers of early mycobacterium avium subsp paratuberculosis infection. PLoS ONE 2015, 10, e0134310. [CrossRef] [PubMed]

15. Wu, F.; Zhang, S.; Dassopoulos, T.; Harris, M.L.; Bayless, T.M.; Meltzer, S.J.; Brant, S.R.; Kwon, J.H. Identification of microRNAs associated with ileal and colonic crohn's disease. Inflamm. Bowel Dis. 2010, 16, 1729-1738. [CrossRef] [PubMed]

16. Paraskevi, A.; Theodoropoulos, G.; Papaconstantinou, I.; Mantzaris, G.; Nikiteas, N.; Gazouli, M. Circulating microRNA in inflammatory bowel disease. J. Crohn's Colitis 2012, 6, 900-904. [CrossRef] [PubMed]

17. De Souza, H.S.; Fiocchi, C. Immunopathogenesis of ibd: Current state of the art. Nat. Rev. Gastroenterol. Hepatol. 2016, 13, 13-27. [CrossRef] [PubMed]

18. Dalal, S.R.; Kwon, J.H. The role of microrna in inflammatory bowel disease. Gastroenterol. Hepatol. 2010, 6, 714 .

19. Chapman, C.G.; Pekow, J. The emerging role of miRNAs in inflammatory bowel disease: A review. Ther. Adv. Gastroenterol. 2015, 8, 4-22. [CrossRef] [PubMed]

20. Liang, G.; Malmuthuge, N.; Griebel, P. Model systems to analyze the role of mirnas and commensal microflora in bovine mucosal immune system development. Mol. Immunol. 2015, 66, 57-67. [CrossRef] [PubMed]

21. Liang, G.; Malmuthuge, N.; Bao, H.; Stothard, P.; Griebel, P.J. Transcriptome analysis reveals regional and temporal differences in mucosal immune system development in the small intestine of neonatal calves. BMC Genet. 2016, 17, 602. [CrossRef] [PubMed]

22. Liang, G.; Malmuthuge, N.; Guan, Y.; Ren, Y.; Griebel, P.J.; Guan, L.L. Altered microrna expression and pre-mRNA splicing events reveal new mechanisms associated with early stage mycobacterium avium subspecies paratuberculosis infection. Sci. Rep. 2016, 6. [CrossRef] [PubMed]

23. Ibeagha-Awemu, E.M.; Do, D.N.; Dudemaine, P.-L.; Fomenky, B.E.; Bissonnette, N. Integration of lncRNA and mrna transcriptome analyses reveals genes and pathways potentially involved in calves' intestinal growth and development during the early weeks of life. Genes 2017. submitted.

24. Do, D.N.; Dudemaine, P.-L.; Fomenky, B.E.; Ibeagha-Awemu, E.M. Integration of miRNA weighted gene co-expression network and miRNA-mRNA co-expression analyses reveals potential regulatory functions of mirnas in calf rumen development. Genomics 2018. [CrossRef] [PubMed]

25. Li, R.; Dudemaine, P.-L.; Zhao, X.; Lei, C.; Ibeagha-Awemu, E.M. Comparative analysis of the mirnome of bovine milk fat, whey and cells. PLoS ONE 2016, 11, e0154129. [CrossRef] [PubMed]

26. Langmead, B.; Trapnell, C.; Pop, M.; Salzberg, S.L. Ultrafast and memory-efficient alignment of short DNA sequences to the human genome. Genet. Biol. 2009, 10, R25. [CrossRef] [PubMed]

27. Friedlander, M.R.; Chen, W.; Adamidi, C.; Maaskola, J.; Einspanier, R.; Knespel, S.; Rajewsky, N. Discovering micrornas from deep sequencing data using mirdeep. Nat. Biotechnol. 2008, 26, 407-415. [CrossRef] [PubMed]

28. Love, M.I.; Huber, W.; Anders, S. Moderated estimation of fold change and dispersion for RNA-seq data with DESeq2. Genet. Biol. 2014, 15, 550. [CrossRef] [PubMed]

29. Benjamini, Y.; Hochberg, Y. Controlling the false discovery rate: A practical and powerful approach to multiple testing. J. R. Stat. Soc. Ser. B (Methodol.) 1995, 57, 289-300.

30. Li, R.; Beaudoin, F.; Ammah, A.A.; Bissonnette, N.; Benchaar, C.; Zhao, X.; Lei, C.; Ibeagha-Awemu, E.M. Deep sequencing shows microrna involvement in bovine mammary gland adaptation to diets supplemented with linseed oil or safflower oil. BMC Genet. 2015, 16, 884. [CrossRef] [PubMed]

31. Bindea, G.; Mlecnik, B.; Hackl, H.; Charoentong, P.; Tosolini, M.; Kirilovsky, A.; Fridman, W.-H.; Pagès, F.; Trajanoski, Z.; Galon, J. Cluego: A cytoscape plug-in to decipher functionally grouped gene ontology and pathway annotation networks. Bioinformatics 2009, 25, 1091-1093. [CrossRef] [PubMed]

32. Shannon, P.; Markiel, A.; Ozier, O.; Baliga, N.S.; Wang, J.T.; Ramage, D.; Amin, N.; Schwikowski, B.; Ideker, T. Cytoscape: A software environment for integrated models of biomolecular interaction networks. Genet. Res. 2003, 13, 2498-2504. [CrossRef] [PubMed]

33. Turner, M.; Galloway, A.; Vigorito, E. Noncoding RNA and its associated proteins as regulatory elements of the immune system. Nat. Immunol. 2014, 15, 484-491. [CrossRef] [PubMed] 
34. Huang, J.; Ju, Z.; Li, Q.; Hou, Q.; Wang, C.; Li, J.; Li, R.; Wang, L.; Sun, T.; Hang, S.; et al. Solexa sequencing of novel and differentially expressed micrornas in testicular and ovarian tissues in holstein cattle. Int. J. Biol. Sci. 2011, 7, 1016-1026. [CrossRef] [PubMed]

35. Liang, G.; Malmuthuge, N.; McFadden, T.B.; Bao, H.; Griebel, P.J.; Stothard, P. Potential regulatory role of micrornas in the development of bovine gastrointestinal tract during early life. PLoS ONE 2014, 9, e92592. [CrossRef] [PubMed]

36. Li, Z.; Liu, H.; Jin, X.; Lo, L.; Liu, J. Expression profiles of micrornas from lactating and non-lactating bovine mammary glands and identification of mirna related to lactation. BMC Genet. 2012, 13, 731. [CrossRef] [PubMed]

37. Bretin, A.; Carriere, J.; Dalmasso, G.; Bergougnoux, A.; B'Chir, W.; Maurin, A.C.; Muller, S.; Seibold, F.; Barnich, N.; Bruhat, A.; et al. Activation of the EIF2AK4-EIF2A/eIF2 $\alpha$-ATF4 pathway triggers autophagy response to crohn disease-associated adherent-invasive Escherichia coli infection. Autophagy 2016, 12, 770-783. [CrossRef] [PubMed]

38. Kim, J.; Kim, J.-H.; Lee, S.-H.; Kim, D.-H.; Kang, H.-Y.; Bae, S.-H.; Pan, Z.-Q.; Seo, Y.-S. The novel human DNA helicase hFBH1 is an F-box protein. J..Biol. Chem. 2002, 277, 24530-24537. [CrossRef] [PubMed]

39. Heyn, H.; Sayols, S.; Moutinho, C.; Vidal, E.; Sanchez-Mut, J.V.; Stefansson Olafur, A.; Nadal, E.; Moran, S.; Eyfjord Jorunn, E.; Gonzalez-Suarez, E.; et al. Linkage of DNA methylation quantitative trait loci to human cancer risk. Cell Rep. 2014, 7, 331-338. [CrossRef] [PubMed]

40. Laulier, C.; Cheng, A.; Huang, N.; Stark, J.M. Mammalian fbh1 is important to restore normal mitotic progression following decatenation stress. DNA Repair 2010, 9, 708-717. [CrossRef] [PubMed]

41. Kopajtich, R.; Nicholls Thomas, J.; Rorbach, J.; Metodiev Metodi, D.; Freisinger, P.; Mandel, H.; Vanlander, A.; Ghezzi, D.; Carrozzo, R.; Taylor Robert, W.; et al. Mutations in gtpbp3 cause a mitochondrial translation defect associated with hypertrophic cardiomyopathy, lactic acidosis, and encephalopathy. Am. J. Hum. Genet. 2014, 95, 708-720. [CrossRef] [PubMed]

42. Tan, Y.; Wang, Q.; Zhao, B.; She, Y.; Bi, X. GNB2 is a mediator of lidocaine-induced apoptosis in rat pheochromocytoma PC12 cells. NeuroToxicol. 2016, 54, 53-64. [CrossRef] [PubMed]

43. Yue, J.; Tigyi, G. Conservation of miR-15a/16-1 and miR-15b/16-2 clusters. Mamm. Genome 2010, $21,88-94$. [CrossRef] [PubMed]

44. Chen, L.; Liu, X.; Li, Z.; Wang, H.; Liu, Y.; He, H.; Yang, J.; Niu, F.; Wang, L.; Guo, J. Expression differences of mirnas and genes on NF-KB pathway between the healthy and the mastitis chinese holstein cows. Gene 2014, 545, 117-125. [CrossRef] [PubMed]

45. Schmid, J.A.; Birbach, A. Ikb kinase $\beta$ (ikk $\beta / \mathrm{ikk} 2 / \mathrm{ikbkb})$-A key molecule in signaling to the transcription factor NF-кB. Cytokine Growth Factor Rev. 2008, 19, 157-165. [CrossRef] [PubMed]

46. Pannicke, U.; Baumann, B.; Fuchs, S.; Henneke, P.; Rensing-Ehl, A.; Rizzi, M.; Janda, A.; Hese, K.; Schlesier, M.; Holzmann, K.; et al. Deficiency of innate and acquired immunity caused by an IKBKB mutation. New Eng. J. Med. 2013, 369, 2504-2514. [CrossRef] [PubMed]

47. Huang, J.; Guo, F.; Zhang, Z.; Zhang, Y.; Wang, X.; Ju, Z.; Yang, C.; Wang, C.; Hou, M.; Zhong, J. PCK1 is negatively regulated by bta-miR-26a, and a single-nucleotide polymorphism in the $3^{\prime}$ untranslated region is involved in semen quality and longevity of holstein bulls. Mol. Reprod. Dev. 2016, 83, 217-225. [CrossRef] [PubMed]

48. Salilew-Wondim, D.; Ahmad, I.; Gebremedhn, S.; Sahadevan, S.; Hossain, M.M.; Rings, F.; Hoelker, M.; Tholen, E.; Neuhoff, C.; Looft, C. The expression pattern of micrornas in granulosa cells of subordinate and dominant follicles during the early luteal phase of the bovine estrous cycle. PLoS ONE 2014, 9, e106795. [CrossRef] [PubMed]

49. Liu, J.; Zhang, J.; Li, Y.; Wang, L.; Sui, B.; Dai, D. MiR-455-5p acts as a novel tumor suppressor in gastric cancer by down-regulating rab18. Gene 2016, 592, 308-315. [CrossRef] [PubMed]

50. Wang, X.P.; Luoreng, Z.M.; Zan, L.S.; Li, F.; Li, N. Bovine miR-146a regulates inflammatory cytokines of bovine mammary epithelial cells via targeting the TRAF6 gene. J. Dairy Sci. 2017, 100, 7648-7658. [CrossRef] [PubMed]

51. Vegh, P.; Magee, D.A.; Nalpas, N.C.; Bryan, K.; McCabe, M.S.; Browne, J.A.; Conlon, K.M.; Gordon, S.V.; Bradley, D.G.; MacHugh, D.E. Microrna profiling of the bovine alveolar macrophage response to mycobacterium bovis infection suggests pathogen survival is enhanced by microrna regulation of endocytosis and lysosome trafficking. Tuberculosis 2015, 95, 60-67. [CrossRef] [PubMed] 
52. Martinez, N.J.; Walhout, A.J. The interplay between transcription factors and micrornas in genome-scale regulatory networks. Bioessays 2009, 31, 435-445. [CrossRef] [PubMed]

53. Hobert, O. Gene regulation by transcription factors and micrornas. Science 2008, 319, 1785-1786. [CrossRef] [PubMed]

54. Shalgi, R.; Lieber, D.; Oren, M.; Pilpel, Y. Global and local architecture of the mammalian microrna-transcription factor regulatory network. PLoS Comput. Biol. 2007, 3, e131. [CrossRef] [PubMed]

55. Fantini, S.; Salsi, V.; Reggiani, L.; Maiorana, A.; Zappavigna, V. The miR-196b mirna inhibits the gata6 intestinal transcription factor and is upregulated in colon cancer patients. Oncotarget 2017, 8, 4747. [CrossRef] [PubMed]

56. Peck, B.C.E.; Sincavage, J.; Feinstein, S.; Mah, A.T.; Simmons, J.G.; Lund, P.K.; Sethupathy, P. MiR-30 family controls proliferation and differentiation of intestinal epithelial cell models by directing a broad gene expression program that includes sox9 and the ubiquitin ligase pathway. J. Biol. Chem. 2016, 291, 15975-15984. [CrossRef] [PubMed]

57. Mazumdar, T.; DeVecchio, J.; Shi, T.; Jones, J.; Agyeman, A.; Houghton, J.A. Hedgehog signaling drives cellular survival in human colon carcinoma cells. Cancer Res. 2011, 71, 1092-1102. [CrossRef] [PubMed]

58. Varjosalo, M.; Taipale, J. Hedgehog: Functions and mechanisms. Genes Dev. 2008, 22, 2454-2472. [CrossRef] [PubMed]

59. Zacharias, W.J.; Madison, B.B.; Kretovich, K.E.; Walton, K.D.; Richards, N.; Udager, A.M.; Li, X.; Gumucio, D.L. Hedgehog signaling controls homeostasis of adult intestinal smooth muscle. Dev. Biol. 2011, 355, 152-162. [CrossRef] [PubMed]

60. Kim, P.; Hettema, E. Multiple pathways for protein transport to peroxisomes. J. Mol. Biol. 2015, 427, 1176-1190. [CrossRef] [PubMed]

(C) 2018 by Her Majesty the Queen in Right of Canada as represented by the Minster of Agriculture and Agri-Food. Licensee MDPI, Basel, Switzerland. This article is an open access article distributed under the terms and conditions of the Creative Commons Attribution (CC BY) license (http://creativecommons.org/licenses/by/4.0/). 